\title{
USO DO MODELO POE (PREVISÃO-OBSERVAÇÃO-EXPLICAÇÃO) APLICANDO AS DISCIPLINAS DE QUÍMICA E MATEMÁTICA EM FAVOR DO MEIO AMBIENTE
}

\author{
POE (PREDICT-OBSERVE-EXPLAIN) TECHNIQUE FOR CONCEPTUAL \\ UNDERSTANDING ABOUT CHEMISTRY AND MATHEMATIC APPLIED TO \\ PRESERVATION OF THE ENVIRONMENT
}

Klenicy Kazumy de Lima Yamaguchi ${ }^{1}$

(iD) ORCID iD: 0000-0001-7998-410X

Elzilene Aquino Araújo ${ }^{2}$

ORCID iD: 0000-0003-2118-4737

\begin{abstract}
RESUMO
O objetivo deste trabalho foi aplicar os conteúdos das disciplinas de Química e de Matemática na elaboração de sabão artesanal visando sensibilizar sobre a preservação do meio ambiente. A metodologia didática usou o conceito construtivista POE (previsão-observação-explicação) com intuito de estimular os alunos a expor seus conhecimentos prévios e posteriormente aplicá-los de forma multidisciplinar. As atividades foram realizadas na Escola Estadual Maria Almeida do Nascimento no município de Coari/Brasil, em uma turma do $2^{\circ}$ ano do ensino médio. As atividades foram divididas em 5 etapas: questionário inicial, aula expositiva, atividade experimental, debate com exposição dos resultados e questionário final. A utilização do tema transversal sobre o meio ambiente no ensino de Química possibilitou que os discentes compreendessem o uso do conteúdo teórico em um panorama mais abrangente, de forma que ao realizarem os cálculos estequiométricos para a elaboração do sabão artesanal eles conseguiram visualizar as reações de esterificação. Além disso, foi dialogado sobre o uso de material poluente e suas possíveis consequências para os rios, bem como as alternativas para utilização desse resíduo. Dessa forma, houve mais conscientização sobre a importância do meio ambiente aplicando o conhecimento de Química e Matemática.
\end{abstract}

Palavras-chave: Transversalidade. Ensino de Química. Coari.

\begin{abstract}
This work aims to use the Chemistry and Mathematics subject an intervention activity in the elaboration of handmade soap to raise awareness about the preservation of the environment. The methodology used addressed applications of the constructivist concept POE (prediction-observation-explanation) in order to encourage students to expose their previous knowledge and then apply them in a multidisciplinary way. The activities were carried out at Maria Almeida do Nascimento School in Coari city / Brazil, in a class of the 2nd year of high school. The activities were divided into 5 stages: Application of the initial questionnaire, lecture, experimental activity and discussion with presentation of results and application of the final questionnaire. The use of the cross-cutting theme about the environment in chemistry teaching allowed students to understand the application of theoretical material in a broader panorama. One can talk about the use of pollutant material and the possible consequences for the rivers, as well as the alternatives for using this material. There was a greater awareness of the importance of the environment and the application of knowledge of chemistry and mathematics. The students were able
\end{abstract}

\footnotetext{
${ }^{1}$ Doutora em Química pela Universidade Federal do Amazonas (UFAM). Professora Adjunta do Instituto de Saúde e Biotecnologia (ISB), Coari, Amazonas, Brasil, CEP: 69460-000. E-mail: klenicy@gmail.com.

${ }^{2}$ Graduada em Ciências: Biologia e Química pela Universidade Federal do Amazonas (UFAM). Professora da SEDUC-AM, Codajás, Amazonas, Brasil, CEP: 69460-000.
} 
to perform stoichiometric calculations to elaborate the handmade soap and were able to visualize the esterification reactions present in the methodology.

Keywords: Transversally. Chemistry teaching. Coari.

\section{INTRODUÇÃO}

No ensino médio uma das maiores dificuldades enfrentadas pelos alunos está relacionada com a falta de compreensão dos assuntos da disciplina de Química, como consequência, os discentes acabam desmotivados. Apesar da importância dessa área de conhecimento, seu estudo ainda é visto com certa aversão pelos alunos, geralmente devido a dificuldade na abstração dos conteúdos (PAULO et al., 2018). Ou seja, os alunos não conseguem visualizar as aplicações dos conceitos teóricos no seu cotidiano, além disso, há o déficit de aprendizagem dos temas que envolvem cálculos matemáticos.

Com o advento tecnológico e a evolução dos conceitos sobre o ensino e a aprendizagem, as disciplinas estão deixando de ser visualizadas de forma individual, reconhecendo o papel interdisciplinar que o conjunto de informações aplicadas podem causar na formação do indivíduo, contribuindo com a educação crítica e reflexiva dele na sociedade. Segundo Goldberg (1998), "educar é transformar, é despertar aptidões e orientá-las para o melhor uso dentro da sociedade em que vive o educando", criando estruturas que permitam expor para os discentes, maneiras que os motivem.

É importante destacar que a Matemática deve ser vista pelo aluno como um conhecimento que pode favorecer o desenvolvimento do seu raciocínio, de suas sensibilidades expressiva e estética, e de sua imaginação. Logo, a proposta dos Parâmetros Curriculares Nacionais (PCN) apresenta instruções necessárias para que sejam desenvolvidos conhecimentos que possam transcender a característica científica ainda no ensino médio (BRASIL, 1998).

O estudo interdisciplinar vem sendo discutido com um certo vigor, pois entre os vários ramos do conhecimento é constatado a necessidade de uma abordagem que leve em conta a transversalidade entre as disciplinas, deixando de lado a visão compartimentada que historicamente a escola tradicional estabeleceu. Diversos trabalhos vêm sendo publicados na literatura sobre o tema com o uso do ambiente escolar em situações problemas condizentes com o meio em que os discentes estão inseridos (RODRIGUES et al., 2018).

As tendências metodológicas didáticas propõem uma interação entre as várias formas do conhecimento com o objetivo de fomentar o aprendizado do aluno através desse consenso. 
Entre elas, a técnica de ensino POE (Previsão-Observação-Explicação) proposto por pesquisadores construtivistas White e Gunstone (1994) e por Nedelsky (1961). Segundo Rosa e Pinho-Alves (2008), a técnica POE diz que:

\begin{abstract}
Predizer é entendido como a formulação de hipóteses, [...] muitas vezes construídas a partir das discussões anteriores, ou mesmo decorrentes das concepções alternativas dos estudantes. (...) Observar está voltado a questões de retomada de experiências vividas, seja ela uma reflexão individual, ou compartilhada com os demais colegas. Nas atividades experimentais, a capacidade de observação dos eventos é uma habilidade fundamental, pois o autocontrole diante do objeto de observação apresentase como indispensável na aprendizagem. [...] Explicar refere-se à retomada das hipóteses iniciais e o confronto com novos conhecimentos. Saber explicitar ideias e formas de pensamento é fundamental para a construção do conhecimento (ROSA e PINHO-ALVES, 2008, p.7).
\end{abstract}

Esse método versa sobre a aplicação de conteúdos escolares em situações reais, dividindo o aporte metodológico em três etapas distintas: a primeira é a previsão através de situações reais onde as ideias individuais dos alunos e os pretextos sobre aquele fenômeno específico são debatidos; a segunda etapa é a observação, em que os alunos expõem sobre o fenômeno a ser analisado e por fim, a terceira etapa, há a explicação harmoniosa do que foi compreendido nas duas outras etapas.

O método explora as ideias prévias dos educandos para melhorar a compreensão e o desenvolvimento cognitivo deles. Segundo Santos e Sasaki (2015), por meio da metodologia ativa de construção POE, pode ser promovido a elucidação das ideias prévias dos aprendizes, proporcionando situações e mecanismos que estimulam o discente a expressar as suas concepções por meio da construção de uma aprendizagem ativa. Com isso, a explicação dos fenômenos, geralmente abstratos, para os próprios alunos, favorece a aprendizagem, transformando-os em protagonistas no processo de educação. Com a aprendizagem construtivista a técnica de ensino POE coloca sobre o aluno a responsabilidade de explicar e debater um fenômeno real usando seus próprios conhecimentos (SANTOS e SASAKI, 2015).

Trabalhos utilizando essa metodologia vêm sendo publicados, como por Barros (1994), Oliveira (2003), Rosa e Pinho-Alves (2008) e Santos e Sasaki (2015) estabelecendo esse recurso didático como alternativa para facilitar o processo de aprendizagem no Brasil, sendo este utilizado em outros países no ensino de Ciências nas universidades já que contribui para o desenvolvimento de um indivíduo mais crítico e participativo na sociedade

Quanto aos conhecimentos matemáticos são necessários para a resolução de diversas situações, principalmente as que norteiam as reações estequiométricas na química, fazendo com que essas disciplinas caminhem juntas nas atividades humanas (PINTO et al, 2018). 
Dessa forma, essa pesquisa teve como objetivo utilizar o tema transversal sobre a preservação do meio ambiente aplicando os conteúdos das disciplinas de Química e Matemática por meio do método POE (Previsão - Observação - Explicação), visando a utilização dos conceitos teóricos no cotidiano do aluno, além de contribuir com a reflexão sobre a conscientização da preservação do meio ambiente por meio do descarte adequado e da utilização adequada dessas substâncias químicas.

\section{PROCEDIMENTOS METODOLOGICOS}

O referido projeto foi desenvolvido em uma pesquisa de campo, utilizando uma abordagem quantitativa e qualitativa. O trabalho foi realizado na Escola Estadual Maria Almeida do Nascimento situada no município de Coari, no Estado do Amazonas, Brasil, envolvendo os educandos da turma do $2^{\text {a }}$ ano do ensino médio no turno vespertino. A amostra foi composta por 44 estudantes, cuja faixa etária estava compreendida entre 16 a 18 anos. Os conteúdos abordados nas disciplinas de Química e Matemática foram reações química, estequiometria, quatro operações, regra de três e conversão de unidade, respectivamente. Por sua vez, foi dividido em cinco etapas de acordo com a metodologia ativa POE :

I) Introdução - Elaboração/aplicação de um questionário com oito perguntas semiestruturadas para diagnosticar a problemática em foco e os conhecimentos prévios dos alunos. Posteriormente, foram ministradas três aulas teóricas investigativas referentes as temáticas: os cálculos estequiométricos e as reações químicas; as quatro operações matemáticas (adição, subtração, multiplicação e divisão); a regra de três e a conversão de unidade. Para tanto, foi entregue uma apostila elaborada com material didático com situações relacionadas ao cotidiano dos alunos de acordo com a metodologia empregada.

II) Previsão- Com o auxílio da apostila os alunos fizeram previsões individuais sobre as questões relacionadas a aplicação dos conteúdos de Matemática e Química, buscando questionar e instigarsobre as reações químicas, os cálculos matemáticos e a conversão de unidade na estequiometria. Em seguida, debateram sobre o meio ambiente e as previsões da aplicação dos conteúdos estudados. Nesta etapa, os pesquisadores procuraram apresentar uma situação real para que os discentes pudessem expor suas ideias e as razões sobre a preservação do meio ambiente (SANTOS \& SASAKI, 2015).

III) Observação - Nesta etapa foi realizada a atividade experimental: "elaboração de sabão artesanal como proposta para preservação do meio ambiente". A atividade foi realizada no Laboratórios de Química Geral e Química Analítica da Universidade Federal do 
Amazonas (UFAM) devido à ausência de laboratório na escola. Os discentes foram divididos em grupos com quatro integrantes cada. Antes da elaboração do sabão, os alunos realizaram cálculos para determinar a quantidade de soluto e solvente necessários para preparar as soluções, assim como a conversão das unidades. A aula foi preparada de forma que os eles pudessem visualizar o fenômeno, e com isso, observar a relação entre a teoria e a prática.

IV) Explicação - No decorrer da aula, os alunos foram incentivados a analisar o que foi visto na observação e previsão, questionando os motivos e as consequências do descarte inadequado de óleos, gorduras e produtos químicos. Os discentes puderam refletir e discutir na forma de debate sobre a importância das proporções de cada um dos reagentes na reação de saponificação. Também foram explicadas as consequências para o meio ambiente, fauna e flora, e quais seriam as formas de descarte adequado dos produtos.

V) Oficina - Nesta etapa os discentes apresentaram o que aprenderam durante a execução do projeto, para os outros alunos da escola em forma de oficina. Eles foram divididos em quatro equipes para apresentação, e por sua vez, cada equipe ficou responsável por um tema, a saber: a importância da química e da matemática no cotidiano e suas relações; preservação do Meio Ambiente; reutilização de materiais poluentes: óleo de cozinha um resíduo poluidor; fabricação de sabão artesanal: como reciclar o óleo já gasto?

Para a execução da atividade os alunos trouxeram painéis, jogos lúdicos, experimento (sabão artesanal) e outros materiais didáticos recicláveis para exemplificar e facilitar suas abordagens sobre o tema. Por fim, houve a aplicação do questionário final para analisar a aceitação da proposta e da evolução conceitual dos alunos.

\section{RESULTADOS E DISCUSSÃO}

\subsection{Questionário inicial-diagnóstico}

O desenvolvimento do trabalho mostrou ser eficiente quanto a participação dos estudantes, visto que que a utilização de metodologias didáticas alternativas somadas a aula expositiva possibilitam a observação dos fenômenos teóricos, ocorrendo a associação com a prática. Com o questionário inicial foi feito um diagnóstico sobre a percepção prévia dos discentes (tabela 1). 
Tabela 1: Dados da avaliação da metodologia dos professores das disciplinas

\begin{tabular}{|c|c|c|}
\hline Questões & Alternativas & Porcentagem (\%) \\
\hline \multirow{3}{*}{$\begin{array}{l}\text { 1.Você tem alguma dificuldade na disciplina de } \\
\text { química? }\end{array}$} & Sim & 27,27 \\
\hline & Não & 18,18 \\
\hline & parcialmente & 54,55 \\
\hline \multirow{3}{*}{$\begin{array}{lll}\text { 2. A metodologia } & \text { que } & \text { o professor (a) } \\
\text { utiliza ajuda no esclarecimento } & \text { dos conteúdos? }\end{array}$} & Sim & 34,10 \\
\hline & Não & 6,81 \\
\hline & Parcialmente & 59,09 \\
\hline \multirow{5}{*}{$\begin{array}{l}\text { 3. A prática interdisciplinar requer a interação de duas } \\
\text { ou mais disciplina, como isso, a disciplina de } \\
\text { Química também envolve outros conteúdos em } \\
\text { relação as demais disciplinas havendo uma ligação } \\
\text { entre elas. Dessa forma, com qual disciplina você } \\
\text { gostaria de estudar junto com a Química? }\end{array}$} & Biologia & 18,18 \\
\hline & Matemática & 54,54 \\
\hline & Física & 9,0 \\
\hline & Português & 13,64 \\
\hline & Outras & 4,55 \\
\hline \multirow{5}{*}{$\begin{array}{l}\text { 4. Quais dos métodos você gostaria que as aulas } \\
\text { ocorressem? }\end{array}$} & Expositiva & 2,27 \\
\hline & $\begin{array}{c}\text { Atividade } \\
\text { Experimental }\end{array}$ & 72,73 \\
\hline & Tradicional & 6,81 \\
\hline & Atividade lúdica & 13,64 \\
\hline & Outras & 4,55 \\
\hline
\end{tabular}

Fonte: Autoras, 2019.

Foi verificado que cerca de $55 \%$ dos alunos apresentaram alguma dificuldade na compreensão dos conteúdos de Química e no entendimento baseados nos métodos didáticos do professor (59\%). Em relação a interdisciplinaridade, as três disciplinas em que os discentes afirmaram que gostariam de ter atividades relacionadas foram: Matemática (55\%), seguida de Biologia (19\%) e Português (14\%). Nesse sentido, a prática interdisciplinar vem como uma importante ferramenta ao fornecer novas perspectivas para o ensino, pois ao trabalhar temas transversais relacionando duas ou mais disciplinas acontece avanço nas ferramentas pedagógicas favorecendo o surgimento de problematizações e novos questionamentos.

De acordo com os alunos, no momento da apresentação do projeto, após a aplicação do questionário inicial, uma das disciplinas que eles têm afinidade quando é trabalhada com a química é a matemática, como relata alguns alunos:

Aluno 1: Na química, os conteúdos exigem cálculos e na disciplina de matemática é a que nos ajuda a apreender os cálculos. 
Aluno 2: A disciplina de matemática pois ela está envolvida com todo e tudo, e a química também.

Aluno 3: Porque eu gosto muito de matemática e entendo melhor que a de química, talvez juntando as duas eu entenda melhor a química.

Os alunos analisados apresentaram preferência por atividade experimentais (72,73\%), conforme os resultados da tabela 1. As atividades experimentais fornecem ao aluno observação dos fenômenos facilitando a aprendizagem dos conceitos e o desenvolvimento de raciocínio lógico. Os participantes da atividade foram estimulados a visualizarem os conceitos teóricos de forma investigativa, sendo que eles apresentaram pré-disposição para aceitarem a atividade prática proposta.

Nesta perspectiva, Cunha (2012) reflete que o uso de experimentação pode contribuir para a ruptura do paradigma dominante, fazendo avançar em diferentes âmbitos, formas alternativas de trabalhos que quebrem com a estrutura tradicional, auxiliando no desenvolvimento da capacidade de entendimento dos assuntos.

\subsection{Metodologia POE}

Nas aulas teóricas ministradas e nos momento de conversa sobre a aplicação dos conteúdos, a partir da técnica de ensino POE, verificou-se que os discentes se sentiam entusiasmados em externarem os conhecimentos pessoais. No entanto, foi perceptível a diferença em conseguir correlacionar com o conteúdo aprendido na disciplina de Química. As aplicações dos cálculos matemáticos foram mais fáceis de serem exemplificados.

Ao serem direcionados para o assunto de preservação do meio ambiente, os alunos apresentaram uma ideia equivocada de que as substâncias químicas eram maléficas para a natureza. Na oportunidade, foi esclarecido sobre os benefícios da utilização das substâncias químicas e foi mostrado como o termo costuma ser usado de forma pejorativa.

Antes da aula prática, na análise do questionário inicial, os alunos conheciam pouco sobre o descarte de óleo de cozinha e as formas de reaproveitamento. Apenas $34,10 \%$ dos estudantes afirmaram que o óleo usado na cozinha não devia ser descartado no meio ambiente. Embora os estudantes tenham afirmado que não poderia ser descartado no esgoto, quando questionados em como eles descartavam o óleo usado na cozinha em suas residências, eles relataram que não colocavam em prática a teoria. Isso pôde ser exemplificado por meio do relato de alguns alunos: 
Aluno 4: "Bom depende, se caso o óleo ainda der para ser utilizado novamente, colocamos em um pote".

Aluno 5: "Depois de ser utilizado, misturo o óleo com a água e jogo na pia”.

Aluno 6: "Jogamos fora mesmo sabendo que existe outros fins recicláveis para ele”.

Aluno 7: "Jogando no ralo da pia. Quando já está velho, tipo, as vezes utilizamos mais de duas vezes, quando vemos que ainda dá para utilizar".

Sobre a melhor maneira de descartar o óleo usado: 47,72\% sabem que precisariam reciclar e 9,10\% reconhecem que descartam na pia, reafirmando a informação anterior. Quando perguntados sobre as consequências trazidas pelo descarte indevido ao meio ambiente: 45,46\% afirmam que poluem o local onde foi descartado, 40,92\% poluem só os rios, seguido de $6,81 \%$ que afirmaram não conhecer as consequências.

Foi percebido por meio desses resultados uma inclinação dos alunos em saber como um resíduo que eles utilizam em sua residência é capaz de causar a poluição. Os resultados evidenciaram a importância da ampliação sobre a Educação Ambiental como uma alternativa de atenuar uma realidade não satisfatória no que se refere o descarte de um resíduo potencialmente poluidor.

Posteriormente foi aplicado o experimento de sabão artesanal (figura 1). Os professores que ministravam as disciplinas (Química e Matemática) estiveram presentes em todas as etapas executadas. Os discentes puderam observar que a Matemática e a Química estavam interligadas por meio dos conteúdos relacionados a estequiometria e as reações químicas. Durante a prática houve revisão dos conteúdos, acompanhamento do desenvolvimento das atividades e incentivo aos alunos participarem. Muitas dúvidas surgiram a medida em que era necessário por em prática os assuntos teóricos. Os discentes sentiram muita dificuldade na aplicação dos cálculos, desde transformações de mililitro em litros até o cálculo de concentração simples. 


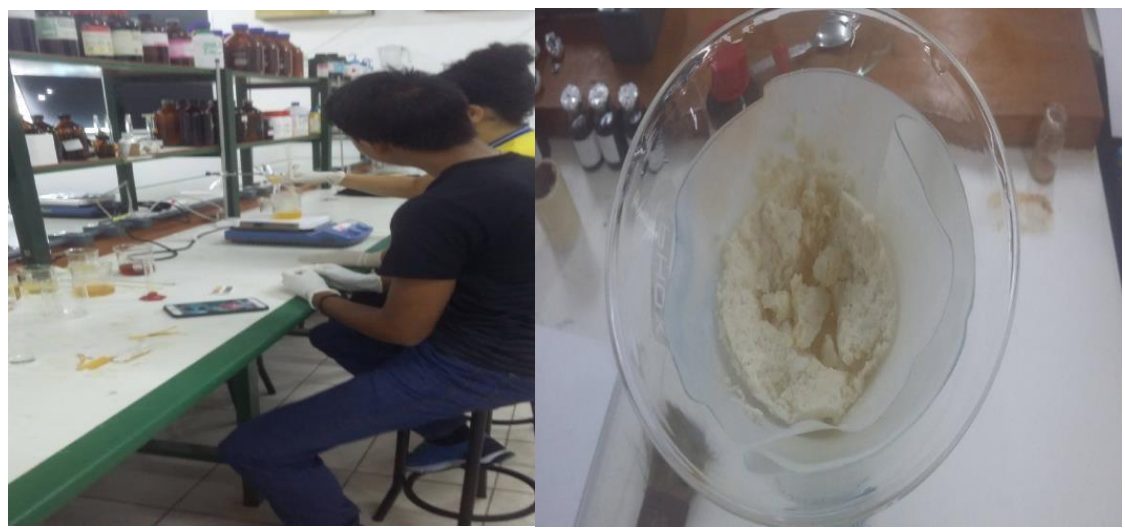

Figura 1: Alunos na atividade prática no laboratório do ISB/UFAM

Fonte: Autoras, 2019.

No decorrer da atividade prática, os discentes demonstraram interesse pelo experimento. Foi observado que a aplicação das duas disciplinas promoveu melhor compreensão sobre a importância da interdisciplinaridade no ensino. De acordo com Schnetzler (2002), as atividades experimentais são relevantes quando caracterizadas pelo seu papel investigativo e sua função pedagógica em auxiliar os alunos na compreensão de fenômenos.

Segundo Fonseca (2001), o trabalho experimental deve estimular o desenvolvimento conceitual, fazendo com que os estudantes explorem, elaborem e supervisionem suas ideias, comparando-as com os conceitos científicos, pois, só assim elas terão papel importante no desenvolvimento cognitivo. Nessa perspectiva, a atividade experimental causou melhora na compreensão conceitual, por aplicarem na prática os conteúdos de matemática e química. $\mathrm{Na}$ análise dos resultados houve aumento no percentual sobre importância da atividade realizada (tabela 2).

Tabela 2: Dados do questionário de avaliação sobre o experimento (sabão artesanal) relacionado ao meio ambiente

\begin{tabular}{c|c|c|c}
\hline \multirow{2}{*}{ Questões } & Alternativas & Questionário inicial (\%) & Questionário final (\%) \\
\hline \multirow{2}{*}{$\begin{array}{c}\text { 1.O óleo de cozinha } \\
\text { devem ser descartado } \\
\text { na natureza? }\end{array}$} & Sim & 31,81 & 0 \\
\cline { 2 - 4 } & Não & 34,10 & 0 \\
\cline { 2 - 4 } & Talvez & 29,55 & 0 \\
\hline \multirow{4}{*}{$\begin{array}{c}\text { 2. Qual a melhor maneira de } \\
\text { descartar o óleo de cozinha } \\
\text { depois de ser utilizado? }\end{array}$} & a) Jogar no esgoto & 4,54 & 0 \\
\cline { 2 - 4 } & b) Descartar na pia & 6,81 & 0 \\
\cline { 2 - 4 } & c) Descartar no lixo & 9,10 & 0 \\
\cline { 2 - 4 } & e) Neciclar o material & 25 & 100 \\
\cline { 2 - 4 } & e) Não responderam & 47,72 & 0 \\
\hline
\end{tabular}




\begin{tabular}{|c|c|c|c|}
\hline \multirow{6}{*}{$\begin{array}{l}\text { 3. E se for descartado no } \\
\text { meio ambiente quais as } \\
\text { consequências? }\end{array}$} & $\begin{array}{l}\text { a) Poluir o local onde foi } \\
\text { descartado }\end{array}$ & 45,46 & 75,5 \\
\hline & b) Poluir os rios & 40,92 & 24,5 \\
\hline & \begin{tabular}{|ll} 
c) Não ocorre & nenhuma \\
consequência & \\
\end{tabular} & 6,81 & 0 \\
\hline & $\begin{array}{l}\text { d) Ajuda } \quad \text { o meio } \\
\text { ambiente }\end{array}$ & 2,27 & 0 \\
\hline & e) Nenhuma das alternativas & 2,27 & 0 \\
\hline & f) Não responderam & 2,27 & 0 \\
\hline \multirow{6}{*}{$\begin{array}{l}\text { 4. Qual é a melhor maneira } \\
\text { de ajudar o meio Ambiente? }\end{array}$} & a) Não jogando lixo & 29,55 & 25,5 \\
\hline & b) Reciclar o lixo & 38,64 & 45,5 \\
\hline & $\begin{array}{l}\text { c)Utilizar novas maneira de } \\
\text { conscientizar a população }\end{array}$ & 6,81 & 29 \\
\hline & d) Deixar como está & 0 & 0 \\
\hline & $\begin{array}{c}\text { e) Fazer a minha partir e as } \\
\text { outras pessoas façam a } \\
\text { delas } \\
\end{array}$ & 25 & 0 \\
\hline & f) Não responderam & 0 & 0 \\
\hline
\end{tabular}

Fonte: Autoras, 2019.

Conforme os resultados expressos na tabela 2, avaliando os dados sobre a atividade experimental, foi verificado que $100 \%$ dos alunos responderam no questionário final que o óleo de cozinha não deve ser descartado e foi unânime que a melhor maneira de utilizar este resíduo é reciclando-o.

A temática proposta teve resultado satisfatório na compreensão na importância de se preservar o meio ambiente, pois os educandos apresentaram uma compreensão mais adequadasobre as consequências trazidas pelo descarte indevido dos resíduos nos locais: 75,5\% afirmam que poderia poluir o ambiente e $24,5 \%$ afirmaram que os rios são os maiores prejudicados. A partir do questionário final, pudemos perceber que os discentes acreditam que a melhor maneira de ajudar o meio ambiente é não jogando o lixo de forma inadequada $(25,5 \%)$, também 45,5\% afirmaram que ele deve ser reciclando e por sua vez, $29 \%$ afirmam que é preciso utilizar diversas maneiras de conscientizar as pessoas. Foi observado mais sensibilização dos alunos sobre Educação Ambiental, havendo uma compreensão adequada dos problemas ambientais, na perspectiva interdisciplinar.

No início do projeto os discentes apresentaram dificuldades em executar alguns exercícios ou atividades referentes ao conteúdo das disciplinas, como a resolução de reação de balanceamento em relação aos coeficientes estequiométricos e cálculos de regra de três simples, 
principalmente quando precisavam converter unidades de medidas. Ao serem avaliados com o questionário final, foi verificado o aumento no acerto das questões. Nos itens sobre reações químicas, houve $100 \%$ de acerto, balanceamento químico $87 \%$ e da estequiometria $88 \%$. Além disso, os discentes conseguiram efetuar os cálculos de todas as questões..

Em relação a apostila, duas questões abordaram o conceito de reações químicas e cálculos matemáticos como: os tipos de reações e a reação de saponificação, ocorrendo um percentual de $81 \%$ de acerto. Nas questões de estequiometria e conversão de unidades, as questões que relacionavam mol com mol os alunos conseguiram acertar 89\%; e as que relacionavam mol com grama $85,7 \%$ de acertos. Pudemos perceber que os educandos compreenderam as relações das grandezas, porém, apresentaram dificuldade em relacionar as grandezas numéricas.

A metodologia utilizada para aplicar o conteúdo de Química e Matemática foi interessante para os discentes ao proporcionar de forma significativa o desenvolvimento do conhecimento cognitivo dos alunos, relacionando a teoria com a prática no contexto ambiental. Essa temática utilizada envolveu e motivou os alunos na aula. Segundo Souza e Justi (2005), os educadores devem buscar diferentes estratégias de ensino em suas áreas de atuação disciplinar, visando ampliar a magnitude do ensino rompendo o paradigma tradicional que rege o processo de aprendizagem de um modo geral.

Os alunos, por sua vez, precisam estar inseridos em um ambiente em que a compreensão dos trâmites entre a construção do saber seja favorecida, principalmente em disciplinas de caráter empírico como a Química e a Matemática (SOUZA, JUSTI, 2005). É importante a procura por novas metodologias que proporcionem o envolvimento dos discentes nas aulas, de forma que busquem por novos saberes e que tomem a inciativa para tomarem decisões que possam incrementar os seus conhecimentos. Segundo Chassot (1995) e Santos e Schnetzler (1996), é papel da escola desenvolver a capacidade de tomada de decisão, formando cidadãos mais críticos e eficientes para intervirem de forma promissora e significativa na sociedade.

O uso da interdisciplinaridade utilizando as disciplinas de Química e de Matemática com temas transversais, ocasionou uma motivação nos discentes. Foi verificado que os alunos conseguiram entender a importância das disciplinas e sua ligação com seu cotidiano. A prática interdisciplinar forneceu o envolvimento das variadas formas do conhecimento, havendo uma interação das disciplinas em prol do ensino e contribuindo para o desenvolvimento do aprendizado. Sendo que a elaboração do sabão artesanal envolveu não apenas conhecimentos específicos da área de Matemática e de Química, como também das outras disciplinas como 
Português, Biologia e Física, pois foi necessário expressar alguns conceitos ligados a educação ambiental.

\subsection{Educação Ambiental: Oficina de fabricação de sabão artesanal.}

Houve um circuito para apresentação das atividades dos alunos. Todos os materiais que os grupos levaram foram confeccionados com materiais recicláveis. A primeira equipe que ficou com o tema “A importância da Química e Matemática no cotidiano e suas relações”, foi adotado uma metodologia lúdica, seguindo com a explicação de um painel com exemplos do cotidiano referentes as aplicações interdisciplinares da Química e da Matemática. Os jogos foram: os "dados matemáticos", em que foram fornecidos dois dados para que os jogadores pudessem apresentar cálculos de multiplicação, divisão, soma e subtração; o "baralho químico", em que os elementos da tabela periódica eram utilizados para realização dos cálculos da massa atômica. A atividade teve o objetivo de apresentar a importância e a aplicação dos cálculos nas duas disciplinas.

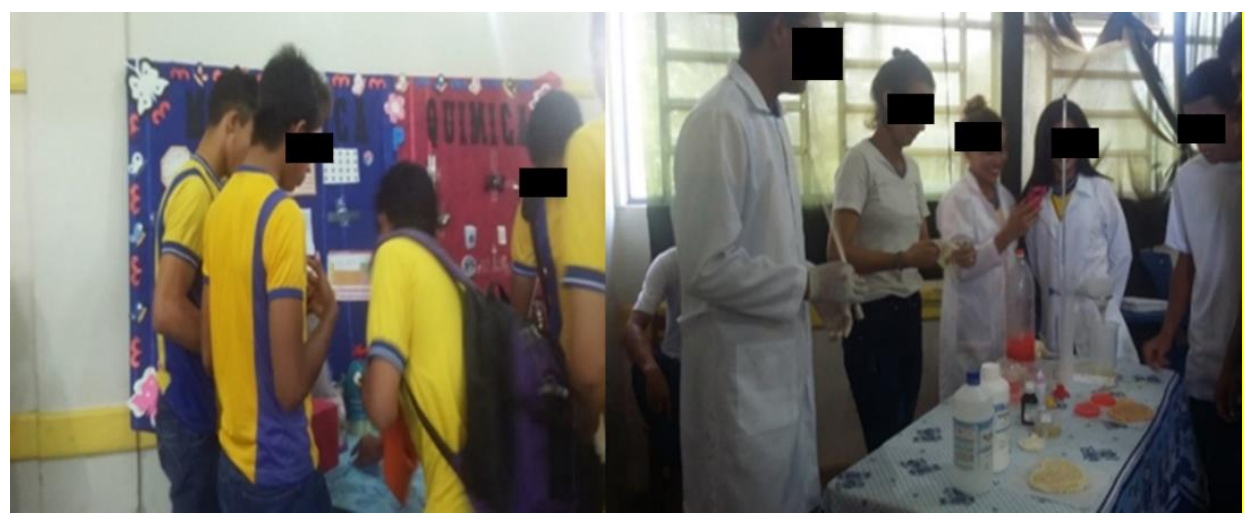

Figura 2: Alunos na apresentação da oficina na escola

Fonte: Autoras, 2019.

A segunda equipe trabalhou o tema "Preservação do Meio Ambiente", nessa foi apresentada uma reflexão sobre o meio ambiente e como o lixo deve ser descartado de forma correta. Em seguida, foi aplicado o jogo "A trilha do conhecimento", uma atividade feita em forma de tabuleiro, dividindo os ouvintes em dois grupos, utilizando a escolha das peças (uma tartaruga e uma flor, ambas feitas de material reciclável) com o objetivo de chegar ao ponto final respondendo perguntas referentes ao tema ambiental.

A terceira equipe usou o tema "Reutilização de materiais Poluentes: óleo de cozinha um resíduo poluidor". Esse grupo ressaltou os benefícios e os malefícios do descarte indevido do óleo de cozinha, expondo em painéis ilustrativos exemplos do que ocorre na prática. 
A última equipe "Fabricação de sabão artesanal: como se deve reciclar o óleo já gasto?", trouxe uma atividade experimental, em que eles precisaram trazer materiais que estavam disponíveis no cotidiano. Após realizarem pesquisas sobre os procedimentos adequados para se fabricar sabão, de forma sucinta, os discentes expuseram o método adaptado de elaboração de sabão artesanal utilizando hidróxido de sódio, óleo de cozinha, álcool etílico (96\%) e uma garrafa pet para misturar as soluções seguindo a metodologia descrita por Moreira et al.,(2014).

Com relação a elaboração dessa atividade, foi percebido uma dificuldade na inserção da prática no ambiente escolar, pois não havia disponível ferramentas necessárias para que a prática ocorresse no local, como a ausência de laboratório, vidrarias e reagentes.

Em relação a educação ambiental, foi verificado que houve uma construção pedagógica voltada para as práticas socioeducativas, sensibilizando os discentes por meio da interação entre a escola, fonte disseminadora de saberes, e a comunidade. Essa é uma tendência que vem sendo implantada com sucesso em outras atividades de intervenção (Cavalcante et al., 2014).

Houve participação dos educandos em todas as atividades, assim como a cooperação dos grupos para realização das oficinas. O trabalho em equipe destacou essa união do conteúdo ministrado em desala de aula ao cotidiano dos alunos , aplicando a teoria de forma motivadora e desenvolvendo a educação ambiental e o Ensino em Química e Matemática de forma plausível, sucinta, esclarecida e facilitadora.

A contextualização possibilitou inserir situações em que os próprios discentes depois das atividades conseguiram associar com o cotidiano, transformando o aluno protagonista do próprio processo de aprendizagem e tirando o foco do professor como mediador do conhecimento.

Segundo, Fazenda (2003) e Nogueira (2003), a aprendizagem significativa é uma nova oportunidade mediante as questões do conhecimento, colocando os aspectos ocultos do ato de aprender e de expressar sobre tais questão. De acordo com Moreira (2006) baseado em Ausubel, a aprendizagem significativa é um processo pelo qual, uma nova informação é relacionada com um aspecto especificamente relevante da estrutura do conhecimento do indivíduo, ou seja, propõe que o educador avalie o que o aluno já sabe e então organize o ensino de acordo com esses conhecimentos. Neste sentido, esse projeto conseguiu cumprir o objetivo proposto, possibilitando a associação do conhecimento pessoal do indivíduo de forma transversal com o tema relacionado das disciplinas de Química e Matemática, proporcionando a aprendizagem significativa para o aluno, contribuindo para a melhoria da comunidade. 


\section{CONSIDERAÇÕES FINAIS}

O presente trabalho demostrou avanços na aprendizagem dos indivíduos participantes do estudo, especialmente na verificação da metodologia construtiva POE mediada pela contextualização. Os alunos puderam participar do processo de construção do seu próprio conhecimento através da elaboração das oficinas com temas transversais e interdisciplinares. A metodologia utilizada incentivou a participação dos discentes por meio das observações, debates e diálogos na sala de aula, promovendo a organização de ideias e proporcionando situações que os estudantes embora já tivessem visto, não conseguiam estabelecer um elo com o conhecimento científico. Assim, os objetivos deste projeto foram alcançados, incentivando os alunos sobre a conscientização de preservar o meio ambiente e na aplicação da transversalidade nas disciplinas de Química e de Matemática por meio da elaboração de sabão reutilizando do óleo de cozinha.

\section{REFERÊNCIAS}

BARROS, S. S. Pontas de prova para o diagnóstico da aprendizagem de Física na escola: Um desafio para o professor. Apostila, Instituto de Física - UFRJ, 1994.

BRASIL (1998). Parâmetros Curriculares Nacionais: Ensino Médio. Ministério da educação. Secretaria de Educação Fundamental. Brasília. Disponível em: http://portal.mec.gov.br/seb/arquivos/pdf/livro01.pdf. Acesso em 13 setembro de 2019.

CAVALCANTE, F. C. S. et al. (2014). Educação ambiental: produção de sabão ecológico na escola nossa senhora aparecida em Campina Grande-PB. Revista Acadêmico Científica, 6(2). $\begin{array}{lllll}\text { Acesso } & \text { em } & 13 & \text { janeiro } & \end{array}$ http://www.revistascire.com.br/artigo/2014/OUTUBRO/educacaoAmientalProducaoDeSabao. df.

CHASSOT, A. I. Catalisando transformações na educação. Ijuí: Unijuí, 1995.

CUNHA, M. B. Jogos no Ensino de Química: Considerações Teóricas para sua Utilização em Sala de Aula. Química Nova na Escola, vol. 34, n. 2, p. 92-98, 2012.

FAZENDA, I. C. Didática e interdisciplinaridade. São Paulo: Papirus, 2003.

FONSECA, M.R.M. Completamente química: química geral, São Paulo, 2001.

GOLDBERG, M. C. Educação e qualidade: repensando conceitos. Revista brasileira de estudos pedagógicos. São Paulo, vol. 79, n.1, p. 35-45, 1998. 
MOREIRA C. Q. et al. Reciclagem de óleo usado para produção de sabão artesanal. In: V congresso Brasileiro de Gestão Ambiental. 24 a 27, 2014, Belo Horizonte. Minas Gerais: IBEAS, 2014.

MOREIRA, M. A. A teoria da aprendizagem significativa e sua implicação em sala de aula. Brasília: UnB, 2006.

NOGUEIRA, N. R. Interdisciplinaridade aplicada. São Paulo: Ética., 2003.

OLIVEIRA, P. R. S. A construção social do conhecimento no ensino aprendizagem de Química. IV Encontro Nacional de Pesquisa em Educação em Ciências, 2003.

PAUlO, P. R. N. F.; BORGES, M. N.; DELOU, C. M. Produção de materiais didáticos acessíveis para o ensino de química orgânica inclusivo. Areté - Revista Amazônica de Ensino de Ciências, Manaus, vol.11, n.23, p. 116-125, 2018.

PINTO, V. L. L. S.; LOZANO, A. R. G.; SIQUEIRA, A. S. Estudos matemáticos em projetos interdisciplinares: o caso da fabricação de detergente. Areté - Revista Amazônica de Ensino de Ciências, Manaus, vol. 11, n.23, p. 109-115, 2018.

RODRIGUES, T. C. T.; FERRARO, J.L.S. HARRES, J.B.S. Praticando a interdisciplinaridade no ambiente escolar com o uso do sensoriamento remoto, geoprocessamento e fotografia. Experiências em Ensino de Ciências, vol. 13, n.5, p. 42-58, 2018.

ROSA, C. W.; PINHO-ALVES, J. (2008) Ferramentas didáticas metacognitivas: alternativas para o ensino de Física. In: ENCONTRO DE PESQUISA EM ENSINO DE FÍSICA, 11, Curitiba. São Paulo: SBF, 2008.

SANTOS, R. J.; SASAKI, D. G. G. Uma metodologia de aprendizagem ativa para o ensino de mecânica em educação de jovens e adultos. Revista Brasileira de Ensino de Física, vol. 37, n.3, p. 1-9, 2015.

SANTOS, W.L.P. e SCHNETZLER, R.P. Ensino de química e cidadania. Química Nova na Escola, vol. 4, n.1, p. 28-34, 1996.

SCHNETZLER, R. P. A Pesquisa em Ensino de Química no Brasil: Conquistas e Perspectivas. Química Nova, vol. 25(s1), n. 14-24, 2002.

SOUZA, V. C. A., JUSTI, R. S. O Ensino de Ciências e seus Desafios Humanos e Científicos: fronteiras entre o saber e o fazer científico, In: Atas do V Encontro Nacional de Pesquisa em Educação em Ciências, Bauru, 2005.

ZULIANI, S. R.Q. A. A utilização da Metodologia Investigativa na Aprendizagem de Química Experimental. Dissertação (Mestrado Em Educação Para A Ciência Curso De PósGraduação Em Educação Para A Ciência (Área De Concentração: Ensino De Ciência), Faculdade de Ciência - Universidade Estadual Paulista Júlio de Mesquita Filho, Bauru, 2000. 
Submetido em: 09 de janeiro de 2020.

Aprovado em: 30 de janeiro de 2020. 